\title{
Rheological characterization of polymer/ceramic blends for 3D printing of bone scaffolds
}

DOI:

10.1016/j.polymertesting.2018.04.033

\section{Document Version}

Accepted author manuscript

Link to publication record in Manchester Research Explorer

\section{Citation for published version (APA):}

Huang, B., \& Bártolo, P. J. (2018). Rheological characterization of polymer/ceramic blends for 3D printing of bone scaffolds. Polymer Testing, 68, 365-378. https://doi.org/10.1016/j.polymertesting.2018.04.033

\section{Published in:}

Polymer Testing

\section{Citing this paper}

Please note that where the full-text provided on Manchester Research Explorer is the Author Accepted Manuscript or Proof version this may differ from the final Published version. If citing, it is advised that you check and use the publisher's definitive version.

\section{General rights}

Copyright and moral rights for the publications made accessible in the Research Explorer are retained by the authors and/or other copyright owners and it is a condition of accessing publications that users recognise and abide by the legal requirements associated with these rights.

\section{Takedown policy}

If you believe that this document breaches copyright please refer to the University of Manchester's Takedown Procedures [http://man.ac.uk/04Y6Bo] or contact uml.scholarlycommunications@manchester.ac.uk providing relevant details, so we can investigate your claim.

\section{OPEN ACCESS}




\section{Manuscript Details}

\section{Manuscript number}

Title

Short title

Article type
POTE_2018_216_R1

Rheological characterization of polymer/ceramic blends for 3D printing of bone scaffolds

Rheology of 3D printing materials

Research Paper

\section{Abstract}

The fabrication of optimized scaffolds for bone regeneration requires complex physical and biological requirements, which strongly depend on the processing conditions and the material morphological development during the fabrication process. This paper presents an extensive rheological characterization of polymer/ceramic blends commonly used for the fabrication of bone scaffolds through additive manufacturing. Poly- $\varepsilon$-caprolactone (PCL)/hydroxyapatite (HA) and PCL/tri-calcium phosphate (TCP) blends with different ceramic contents $(5,10$ and $20 \mathrm{wt} \%)$ were prepared using melt blending and studied using rotational and oscillation rheological tests. Results show that all samples present a shearthinning behavior making them suitable for additive manufacturing. All samples present a viscoelastic behaviour with significantly high viscous modulus than elastic modulus at low frequencies. Both modulus increases with the addition of ceramic particles. Results also show that PCL/HA samples present high elastic modulus than PCL/TCP.

\section{Keywords}

\section{Manuscript category}

Corresponding Author

Corresponding Author's Institution

Order of Authors

Suggested reviewers
Additive manufacturing; polymer-ceramic blends; printability; rheology

PLASTICS (chemical analysis including chemical analysis of Rubbers, polymers used in biomedical applications, scattering, spectroscopy, NMR)

Paulo Bartolo

University of Manchester

boyang huang, Paulo Bartolo

Rodrigo Rezende, Rangam Rajkhowa, Antonio Pontes

\section{Submission Files Included in this PDF}

\section{File Name [File Type]}

Response to the reviewers.docx [Response to Reviewers]

Highlights.docx [Highlights]

Manuscript.docx [Manuscript File]

To view all the submission files, including those not included in the PDF, click on the manuscript title on your EVISE Homepage, then click 'Download zip file'. 


\section{RESPONSE TO THE REVIEWERS}

Authors appreciate the careful review of this manuscript and the relevance of the comments that allow to improve its quality.

\section{$\underline{\text { Reviewers comments and answers }}$}

This paper makes a practical contribution to the development of polymer/ceramic blends for $3 \mathrm{D}$ printing. I only have some relatively minor suggestions.

The authors state that " The difference between both modulus is higher at lower frequencies becoming closer at higher frequencies, making a shift from a "liquid-like" component to a "solid-like" one." Is this the case or just that for liquids the loss modulus is linear with frequency but the storage should go as the square of frequency and therefore they will become closer as the frequency increases? There is no change in the dependence of storage and loss modulus with frequency what suggest that there is no change in the basic structure of the material?

The comment is valid and the manuscript was modified according to the reviewer comments. A new table showing the slop values of the storage modulus versus frequency and loss modulus versus frequency curves was added.

As the blend leaves the nozzle during printing it will also cool down. How will this affect the process?

The comment is pertinent. After the extrusion, the material will cool down and recrystallize forming higher ordered structures. However, material recrystallization, which has a significant effect on the final properties of produced 3D printed structures, was not considered in this manuscript. Our focus was only on the melt rheological behaviour and printability characteristics of the blends prior cooling.

The effect of temperature in the storage and loss modulus is shown in Fig. 3 not Fig 4. The manuscript was modified according to the reviewer comments.

Perhaps the authors could comment a bit more on the role of the particle size distribution and particle size. The HA seems to have a wider distribution and more irregular particles. Will this affect much the rheology at these relatively low volume fractions of ceramic? TCP seems to have relatively small primary particles $(<0.5$ microns) that form agglomerates (these are the ones measured in the particle size distribution). Will this agglomerates break during mixing with the polymer blend?

The reviewer comments are relevant. Particle size seems to have an effect on the shear viscosity. As mentioned in the manuscript the shear viscosity increases by increasing the 
ceramic content. For the same ceramic content, HA blends present higher viscosities, which can be attributed to the larger specific surface area that increases the interactions with the polymer chains. However from the obtained results it is not possible to infer any correlation between shear viscosity and particle size distribution.

Based on the obtained results, it seems that the effect of the agglomeration tendency of TCP on the reheological behaviour of the blends is insignificant. 


\section{Highlights}

- PCL/HA and PCL/TCP blends containing a maximum of $20 \mathrm{wt} \%$ of ceramic particles present appropriate printability characteristics for additive biomanufacturing.

- Cole-cole plot results show good compatibility between PCL and both HA and TCP.

- PCL/TCP samples present low viscosity being easy to process.

- At low frequencies, PCL/HA blends present higher elastic modulus than PCL/TCP for the same ceramic content.

- For all samples the viscous modulus is higher than the elastic modulus, with the difference between them decreasing by increasing frequency. 


\title{
Rheological characterization of polymer/ceramic blends for 3D printing of bone scaffolds
}

\author{
Boyang Huang, Paulo Bártolo*
}

School of Mechanical, Aerospace and Civil Engineering, University of Manchester, Manchester, UK

*Corresponding author: paulojorge.dasilvabartolo@manchester.ac.uk; Tel.: +44 1613064887 


\section{Abstract}

The fabrication of optimized scaffolds for bone regeneration requires complex physical and biological requirements, which strongly depend on the processing conditions and the material morphological development during the fabrication process. This paper presents an extensive rheological characterization of polymer/ceramic blends commonly used for the fabrication of bone scaffolds through additive manufacturing. Poly-e-caprolactone (PCL)/hydroxyapatite (HA) and PCL/tricalcium phosphate (TCP) blends with different ceramic contents (5, 10 and $20 \mathrm{wt} \%)$ were prepared using melt blending and studied using rotational and oscillation rheological tests. Results show that all samples present a shear-thinning behavior making them suitable for additive manufacturing. All samples present a viscoelastic behaviour with significantly high viscous modulus than elastic modulus at low frequencies. Both modulus increases with the addition of ceramic particles. Results also show that PCL/HA samples present high elastic modulus than PCL/TCP.

Keywords: Additive manufacturing; polymer-ceramic blends; printability; rheology

\section{Introduction}

Biomanufacturing is a recent approach developed to support tissue engineering. It is based on the use of additive manufacturing, biomaterials, cells, and biomolecular signals to produce tissue constructs [1-5]. Two different methods are commonly explored, including the use of bioinks (e.g. hydrogels encapsulating cells) to produce cell-laden constructs or the fabrication of three-dimensional structures (scaffolds) to 
support cell attachment, proliferation and differentiation [6-10]. This scaffold-based approach is the most common one [11]. Scaffolds are 3D fully interconnected porous structures, biocompatible and biodegradable with appropriate mechanical and surface properties $[12,13]$.

Screw-assisted extrusion additive manufacturing systems have been extensively used to produce bone scaffolds in a wide range of polymers and polymer/ceramic composites [14-16]. Through this technique, the material is melted by heating and deposited by a numerical-controlled printing device (Figure 1a). The material leaves the extruder in a liquid form and hardens immediately in a working platform.

Bone is an organic- inorganic composite tissue, which consists of $60-70 \%$ of mineral, $10-20 \%$ of collagen and $9-20 \%$ of water by weight. Therefore, organic/inorganic scaffolds, such as poly( $\varepsilon$-caprolactone) (PCL)/hydroxyapatite (HA) and PCL/tricalcium phosphate (TCP) have been extensively investigated. PCL is used due to its biocompatibility, mechanical properties and easy to process characteristics $[17,18]$. Hydroxyapatite presents a similar mineral structure to natural bone. It is an osteoconductive material that allows the formation of a high connection with the surrounding bone tissue [19-21]. TCP is a biocompatible ceramic, osteoconductive and bioresorbable $[19,21,22]$. The major drawbacks of these bioceramic materials are their brittleness and low mechanical stability which are the main reasons for their combination with PCL.

Experimental results demonstrated that there is a strong relationship between processing conditions and both mechanical and biological properties of produced 
scaffolds. Processing conditions also affect the final scaffold architecture (e.g. filament diameter and pore size). Moreover, material characteristics are fundamental to determine the optimum processing parameters (e.g. pressure, temperature and screw rotational velocity). Additionally, the screw-assisted extrusion process is associated with a phase change transformation on the material (solid $\rightarrow$ melt $\rightarrow$ solid) and significant changes on the polymer chain orientation (Figure 1b) with consequences in terms of shrinkage, crystallinity level and crystal orientation, and mechanical properties [23]. Therefore, it is fundamental to understand the viscoelasticity and the shear-thinning characteristics of the pre-processed materials. However, most of the studies focus on the post-process phase, and a lack of understanding of the rheological behavior of materials for additive manufacturing still exists. This paper investigates this behavior considering the most common materials used for bone applications. The study not only characterizes the printability characteristics of PCL but also the effect of the presence of HA and TCP which have an impact on the rheological behavior of the polymer.

\section{"Insert Figure 1"}

\section{Materials and methods}

\subsection{Materials}

PCL, a semi-crystalline polyester, was supplied by Perstorp Caprolactones (UK). It has a low melting point of around $60^{\circ} \mathrm{C}$ and glass transition temperature of $-60^{\circ} \mathrm{C}$. The material was used in the form of pellets (average size $3 \mathrm{~mm}$ ). Hydroxyapatite (HA) and $\beta$-tricalcium phosphate ( $\beta$-TCP) were supplied by Sigma-Aldrich (USA). The 
average particle size and shape was assessed by particle size analyzer and scanning electron microscopy (SEM) using Mastersizer 3000 (UK) and JSM-6490LV (USA) respectively.

\subsection{Blends preparation}

PCL/HA and PCL/TCP blends using three different concentrations of bioceramics (5, 10 and $20 \mathrm{wt} \%$ ) were prepared using melt blending. Briefly, PCL pellets were heated at $100^{\circ} \mathrm{C}$ in a bowl to guarantee that all material was in a molten state then adding the bioceramic material. The material was mixed for 30 minutes to obtain a uniform mixture and cooled down at room temperature. After cooling, the blended material was cut into small pellets. The efficiency of the mixing process was assessed using thermal gravimetric analysis (TGA). The obtained results are presented in Table 1.

\section{"Insert Table 1"}

\subsection{Rheological analyses}

Dynamic rheological analyses were carried out using the DHR2 TA Instrument (UK). Two different tests (rotational and oscillation) were considered. A parallel plate with a diameter of $20 \mathrm{~mm}$ was used and the gap distance between the parallel-plate geometry was set at $500 \mu \mathrm{m}$. The analyses were carried out at three different temperatures $(80$, 90 and $100^{\circ} \mathrm{C}$ ) considering a melting time of 25 mins to ensure the blends were completely melted. The frequency varied between $10 \mathrm{~Hz}$ to $0.01 \mathrm{~Hz}$ with a constant strain rate of $1 \%$ in the oscillation test. The shear rate was set in the range of 0.01 to $100 s^{-1}$ for the rotational test. Experiments were performed in triplicate.

Oscillatory tests were used to determine the viscoelastic characteristics of all blends, 
by measuring the deformation energy stored (storage modulus, $G^{\prime}$ ) in the material under shearing conditions and the deformation energy subsequently released (loss modulus, $\left.\mathrm{G}^{\prime \prime}\right)$. The storage modulus represents the material elastic behavior while the loss modulus represents the viscous behavior. The loss factor (damping factor) is defined by the ratio between $\mathrm{G}^{\prime \prime}$ and $\mathrm{G}^{\prime}$ as follows:

$$
\tan \delta=G^{\prime \prime} / G^{\prime}
$$

where $\delta$ is the phase shift angle ranging between $0^{\circ}$ and $90^{\circ}$.

Rotational tests were considered to evaluate viscosity and material strength. In these tests, it is assumed that the material flows by applying a stress being the response measured alongside time or temperature. The ideal viscous (or Newtonian) behavior is described by the Newton's law:

$$
\tau=\eta \cdot \dot{\gamma}
$$

where $\tau$ is the shear stress $(\mathrm{Pa}), \eta$ is the viscosity $(\mathrm{Pa} \cdot \mathrm{s})$ and $\dot{\gamma}$ is the shear rate $\left(s^{-1}\right.$ ). For non-Newtonian fluids, a power-law model must be considered:

$$
\tau=\eta \dot{\gamma}^{n}
$$

where $\eta$ is the flow coefficient or consistency $\left(\mathrm{Pa}^{\mathrm{n}}\right)$ and $\mathrm{n}$ is the power law index (dimensionless). Depending on the value of $\mathrm{n}$, different regions can be identified:

$\mathrm{n}<1$ : shear-thinning system

$\mathrm{n}=1$ : Newtonian system

$\mathrm{n}>1$ : shear-thickening system

\section{Results and discussion}

\subsection{Oscillation rheology analysis}

Figure 2 (a-h) shows the variation of both loss and storage modulus for all blends as a function of frequency for a fixed temperature of $80^{\circ} \mathrm{C}$. In all cases, both storage 
modulus and loss modulus increase with increasing frequency. The increase of the dynamic moduli is due to the fact that at a low frequency region, the entangled polymeric chains have enough time to unfold and relax slowly while the shortage of relaxation time for polymer chains to re-orientate leads to higher modulus with increasing the deformation rate. For all samples, the storage modulus is lower than the loss modulus, indicating that the viscous behavior is the dominant effect. The difference between both modulus is higher at lower frequencies becoming closer at higher frequencies, making a shift from a "liquid-like" component to a "solid-like" one. A comparison is provided in Figure $2 \mathrm{~h}$ showing that, at the same frequency, the addition of ceramic particles increases both the loss and the storage modulus. At low frequencies, blends of PCL/HA presents higher storage modulus than PCL and PCL/TCP for the same ceramic content. This difference tends to reduce by increasing frequency. No significant differences were obtained for the loss modulus of PCL/HA and PCL/TCP blends. However, composite blends present higher loss modulus than PCL. As observed, PCL shows a classical homopolymer-like terminal behaviour with the loss modulus increasing almost linearly with frequency $\left(G^{\prime}, \sim f\right)$ and the storage modulus increasing with the square of frequency $\left(\mathrm{G}^{\prime} \sim \mathrm{f}^{2}\right)$. Table 2 presents the slope values of the storage modulus and loss modulus curves against frequency for low regimes $(0.01-1 \mathrm{~Hz})$. No significant differences are observed between PCL and PCL/TCP blends indicating no significant material structure changes. However, in the case of PCL/HA blends the slop values of the storage modulus versus frequency curves are smaller than the PCL or PCL/TCP blends. This might be attributed to HA 
agglomeration restraining the long-scale motion of the polymer chains. However, at high frequencies $(1-10 \mathrm{~Hz})$, this effect is relatively weaker indicating that the addition of ceramics does not significantly influence the short-range dynamics of PCL chains. In terms of printability, PCL/HA blends show stronger elastic behavior than PCL/TCP at low frequencies, which corresponds to a high resistance against deformation during the printing process. However, this difference is minimized by increasing the deformation frequency. This behavior can be correlated with the filament formation after the needle (Figure 1b). Initially, the polymer chains are aligned and decoiled alongside the direction of the needle. However, due to the pressure drop, the alignment along the flow direction tends to decrease and, finally, the polymer chains have longer relaxation time, which depends on the distance between the needle and the printing platform, leading to long-range motions and eventually swelling in the filament diameter. This effect can potentially be minimized through the addition of ceramic particles that will contribute to an increase in both the loss and storage modulus, making difficult polymer chains to recover their shape. The effect of temperature is presented in Figure 3. Results show that for all materials both storage and loss modulus decrease by increasing temperature. This might be caused by the effect of temperature on polymer chain motions and threshold energy of disentanglements. However, the overall viscoelastic behavior is not altered by changing the temperature as the loss modulus and storage modulus are still presenting the same trend for different temperatures.

\section{"Insert Figure 2"}




\section{"Insert Figure 3"}

\section{"Insert Table 2"}

The effect of material composition on the loss factor $(\tan \delta)$ is presented in Figure 4. The results were obtained for a fixed temperature of $80^{\circ} \mathrm{C}$. Similarly, Figure 5 shows the effect of temperature on the loss factor for all material systems. As observed, the loss factor decreases with the increase of the deformation rate, indicating that the viscous effect is becoming less significant than the elastic effect. In terms of printability, results show that all samples are becoming resistant to flow, which means that higher strength and stress are required to lead polymer chains to move. However, at low frequencies, the loss factor decreases with the increase of HA (Figure 4a). This effect tends to disappear with the increase of frequency. Therefore, at high frequencies, the effect of the deformation rate dominates the effect of increasing the ceramic content. However, as shown in Figure 4b, there are no significant difference between PCL and PCL/TCP. These results confirm that, for the same bioceramic content and processing conditions, it is easier to print PCL/TCP than PCL/HA. Results also show that, at the same frequency, the loss factor increases by increasing the temperature (Figure 5).

\section{"Insert Figure 4" \\ "Insert Figure 5"}

\subsection{Cole-cole plot analysis}

The phase homogeneity of different polymer/ceramic blends can be derived from the Cole-cole plot where the imaginary component of the complex viscosity $\eta$ "is plotted 
as function of the real part $\eta^{\prime}$. The imaginary viscosity and real viscosity can be determined as follows:

$$
\begin{aligned}
& \eta^{\prime \prime}=G^{\prime} / w \\
& \eta^{\prime}=G^{\prime \prime} / w
\end{aligned}
$$

where $G^{\prime}$ is the storage modulus, $G^{\prime}$ ' is the loss modulus and $w$ is the frequency determined through oscillation rheological tests.

For a homogeneous phase, a semi-circle shape can be obtained with a well-defined relaxation time (Figure 6). Any deviation from the Cole-cole plot indicates nonhomogeneous dispersion [24]. In addition, the Cole-cole plot also allows determining relevant rheological parameters such as the zero shear viscosity $\eta_{0}$ (limiting value of the shear rate-dependent viscosity at an infinitely low shear rate), and relaxation time $\tau_{c}$ (the time required for polymer chains to recover to equilibrium state). The zero shear viscosity can be determined by fitting the Cole-cole plot and extrapolating to the x-axis $\left(\eta^{\prime}\right.$ at $\left.\eta^{\prime \prime}=0\right)$ whereas the relaxation time corresponds to the inverse of the frequency $[25,26]$. Moreover, this type of representation can be also used for detecting the compatibility of polymer blends. A single curve can be obtained if the blend is compatible, independent of the composition of the blend [26].

\section{"Insert Figure 6"}

Well-defined quarter-circle plots were obtained for all samples at low frequency regimes (Figure 7), indicating homogeneous dispersion of ceramic particles in the PCL matrix. Through the incorporation of ceramic particles, it is possible to observed a larger arc for both PCL/HA and PCL/TCP samples in comparison to PCL, 
indicating a broader relaxation time and higher zero-shear viscosity. Consequently, these samples require higher stresses and longer time to re-orient and disentangle the polymer chains. Results also show that by increasing the ceramic content the elastic behaviour increases, reducing the material flowability. For the same concentration and temperature, TCP samples show smaller relaxation times and zero-shear viscosities than HA samples, presenting a more significant viscous behaviour. It is also possible to observe that by increasing the temperature, the arcs become flattening indicating that the viscous behaviour is strengthening, which facilitates the printing behaviour.

\section{"Insert Figure 7"}

Figures 8 describe the compatibility between PCL and ceramic particles. From Figure $8 \mathrm{a}$, it is possible to observe that at $80^{\circ} \mathrm{C}$, an approximate single curve is obtained for all samples. Although, a deviation occurs at low frequencies particularly for samples containing high ceramic contents due to particle agglomeration. The effects of temperature for PCL/HA and PCL/TCP samples are shown in Figure $8 \mathrm{~b}$ and Figure 8c. A narrow single curve is obtained for TCP samples at different temperatures, indicating high miscibility of PCL/TCP, while a high deviation occurs in HA samples at low frequencies. This might be caused by the larger specific surface area of HA.

\section{"Insert Figure 8"}

\section{Rotational analysis}

\subsection{The effect of temperature and deformation rate on viscosity}

Figure 9 presents the variation of viscosity as a function of shear rate and temperature for all samples. As expected, the results show that the viscosity decreases with the 
increase of temperature. This is due to the increase of the "free volume", facilitating the movement of polymer chains. The increase in temperature also facilitates the reorientation and disentanglement of polymer chains, which strengthens and extends the Newtonian regime observed for low shear rate regions. It is possible to observe a sharply decrease of viscosity after a critical value. Moreover, at low shear rates, temperature is the dominant effect on the viscosity. This effect tends to reduce by increasing the shear rate.

\section{"Insert Figure 9"}

\subsection{The effect of bioceramic contents on viscosity}

Figure 10 shows the effect of HA and TCP contents on the viscosity at different temperatures. From Figure 10a, it can be observed that the addition of ceramic particles can significantly increase the viscosity of the blends at low shear rate regimes, which might be caused by both ceramic-polymer and ceramic-ceramic interactions. The increase of ceramic content, increases the surface area for interactions between inorganic particles and polymer chains, increasing viscosity. However, as the shear rate increases, the entanglement of polymer chains prevail the effect of the material interaction and consequently no significant differences are observed between the different concentrations in terms of viscosity. For all samples, the viscosity decreases with the increase of temperature as discussed in the previous section. Moreover, from Figure 10a to $10 \mathrm{c}$, it seems that the increase of temperature can slightly minimise the effect of bioceramic content on the shear viscosity at low frequency region. The reason for this might be related to the change of the polymer 
volume which reduces material interactions.

\section{"Insert Figure 10"}

\subsection{The effect of particle properties on viscosity}

Particle type, morphology, concentration and distribution are significant factors determining the rheological properties [27]. The particle size distribution of both HA and TCP is shown in Table 3 and Figure 11. The morphology of both HA and TCP particles are shown in Figure 12. The results show that the average particle size for HA particles is $3.41 \mu \mathrm{m}$ while TCP particle presents larger average particle size of $16.10 \mu \mathrm{m}$. It is also possible to observe that HA particles tend to aggregate. Figure 13 shows the effects of particle properties on the flow behaviour of all samples at different temperatures. The addition of ceramics into the PCL matrix leads to the increase of viscosity, and a decrease of the fluidity due to flow resistance. Similar behaviour was previously reported [27-29]. However, the presence of ceramic particles does not change the shear thinning behaviour of PCL, which is a relevant characteristic for $3 \mathrm{D}$ printing. Figure $13 \mathrm{a}$ shows that, for a temperature of $80^{\circ} \mathrm{C}$ and low shear rates, PCL blends containing $20 \mathrm{wt} \%$ of HA presents higher viscosity than PCL blends containing $20 \mathrm{wt} \%$ of TCP. The reason might be related to the smaller particle size of HA, leading to a larger surface area and high interactions with PCL. As expected, for the same temperature, viscosity significantly decreases as the shear rate increases. Thus, the effect of particle characteristics become less pronounced, as the composite materials become predominantly governed by the polymer behaviour [30]. Moreover, results also show that temperature can minimise the effect of particle 
size and type even in the low shear rate region (Figure 13b and Figure 13c).

"Insert Figure 11"

"Insert Figure 12"

"Insert Figure 13"

"Insert Table 3" 


\section{Conclusions}

The use of additive biomanufacturing systems to produce synthetic graphs for bone applications represents a viable approach to current autograft, allograft and xenograft strategies. Due to the chemical structure of bone, PCL/HA and PCL/TCP are relevant materials. The use of these materials for additive biomanufacturing requires a deep understanding of their rheological behaviour. The viscoelastic properties and shear thinning behaviour are relevant characteristics to guarantee good printability and shape fidelity.

PCL blends containing different contents of both HA and TCP were prepared by melt blending. A maximum of $20 \mathrm{wt} \%$ of ceramic particles was considered as higher values make it difficult to print the materials. Results show that all compositions present a shear thinning behaviour, making them appropriate for additive biomanufacturing. Moreover, it is possible to observe that the addition of ceramic particles has no significant effect on this behaviour. The viscosity is strongly dependent on the shear rate and temperature which can be correlated with printing parameters like rotational screw velocity and processing temperature respectively.

All samples present a viscoelastic behaviour with significantly high viscous modulus than elastic modulus at low frequencies. This difference tends to reduce by increasing frequency. Both modulus increases with the addition of ceramic particles. Results also show that PCL/HA samples present high elastic modulus than PCL/TCP. Composite samples show longer relaxation time than PCL samples. Moreover, it was also 
possible to observe that PCL/HA samples present high elastic modulus than PCL/TCP samples, indicating strong resistance against deformation.

Particle size seems to have an effect on the shear viscosity. Results show that the shear viscosity increases by increasing the ceramic content. For the same ceramic content, HA blends present higher viscosities, which can be attributed to the larger specific surface area that increases the interactions with the polymer chains. From the obtained results it is not possible to infer any correlation between shear viscosity and particle size distribution.

\section{Reference}

[1] B. Guillotin, F. Guillemot, Cell patterning technologies for organotypic tissue fabrication, Trends in Biotechnology, 29 (2011) 183-190.

[2] M.W. Laschke, M.D. Menger, Life is 3D: boosting spheroid function for tissue engineering, Trends in Biotechnology, 35 (2017) 133-144.

[3] L. Roseti, V. Parisi, M. Petretta, C. Cavallo, G. Desando, I. Bartolotti, B. Grigolo, Scaffolds for Bone Tissue Engineering: State of the art and new perspectives, Materials Science and Engineering: C, 78 (2017) 1246-1262.

[4] F.P. Melchels, M.A. Domingos, T.J. Klein, J. Malda, P.J. Bartolo, D.W. Hutmacher, Additive manufacturing of tissues and organs, Progress in Polymer Science, 37 (2012) 1079-1104.

[5] P. Bartolo, J.-P. Kruth, J. Silva, G. Levy, A. Malshe, K. Rajurkar, M. Mitsuishi, J. Ciurana, M. Leu, Biomedical production of implants by additive electro-chemical and physical processes, CIRP Annals-Manufacturing Technology, 61 (2012) 635-655. 
[6] R.F. Pereira, C.C. Barrias, P.J. Bártolo, P.L. Granja, Cell-instructive pectin hydrogels crosslinked via thiol-norbornene photo-click chemistry for skin tissue engineering, Acta Biomaterialia, 66 (2018) 282-293.

[7] R.F. Pereira, A. Sousa, C.C. Barrias, A. Bayat, P.L. Granja, P.J. Bártolo, Advances in bioprinted cell-laden hydrogels for skin tissue engineering, Biomanufacturing Reviews, 2 (2017) 1-26.

[8] R.F. Pereira, P.J. Bártolo, 3D bioprinting of photocrosslinkable hydrogel constructs, Journal of Applied Polymer Science, 132 (2015).

[9] F. Pati, J. Gantelius, H.A. Svahn, 3D bioprinting of tissue/organ models, Angewandte Chemie International Edition, 55 (2016) 4650-4665.

[10] S.V. Murphy, A. Atala, 3D bioprinting of tissues and organs, Nature biotechnology, 32 (2014) 773.

[11] C. Vyas, R. Pereira, B. Huang, F. Liu, W. Wang, P. Bartolo, Engineering the vasculature with additive manufacturing, Current Opinion in Biomedical Engineering, $2(2017) 1-13$.

[12] P. Danilevicius, L. Georgiadi, C.J. Pateman, F. Claeyssens, M. Chatzinikolaidou, M. Farsari, The effect of porosity on cell ingrowth into accurately defined, lasermade, polylactide-based 3D scaffolds, Applied Surface Science, 336 (2015) 2-10.

[13] P. Bártolo, C. Chua, H. Almeida, S. Chou, A. Lim, Biomanufacturing for tissue engineering: present and future trends, Virtual and Physical Prototyping, 4 (2009) 203-216.

[14] B. Huang, G. Caetano, C. Vyas, J.J. Blaker, C. Diver, P. Bártolo, Polymer- 
Ceramic Composite Scaffolds: The Effect of Hydroxyapatite and $\beta$-tri-Calcium Phosphate, Materials, 11 (2018) 129.

[15] W. Wang, G.F. Caetano, W.-H. Chiang, A.L. Braz, J.J. Blaker, M.A.C. Frade, P.J.D.S. Bartolo, Morphological, mechanical and biological assessment of PCL/pristine graphene scaffolds for bone regeneration, International Journal of Bioprinting, 2 (2016) 204-213.

[16] G. Caetano, R. Violante, A.B. Sant, A.B. Murashima, M. Domingos, A. Gibson, P. Bártolo, M.A. Frade, Cellularized versus decellularized scaffolds for bone regeneration, Materials Letters, 182 (2016) 318-322.

[17] T.K. Dash, V.B. Konkimalla, Poly-€-caprolactone based formulations for drug delivery and tissue engineering: A review, Journal of Controlled Release, 158 (2012) 15-33.

[18] M.A. Woodruff, D.W. Hutmacher, The return of a forgotten polymerpolycaprolactone in the 21st century, Progress in Polymer Science, 35 (2010) 12171256.

[19] S. Best, A. Porter, E. Thian, J. Huang, Bioceramics: past, present and for the future, Journal of the European Ceramic Society, 28 (2008) 1319-1327.

[20] C.E. Corcione, F. Gervaso, F. Scalera, F. Montagna, T. Maiullaro, A. Sannino, A. Maffezzoli, 3D printing of hydroxyapatite polymer-based composites for bone tissue engineering, Journal of Polymer Engineering, 37 (2017) 741-746.

[21] S.V. Dorozhkin, Calcium orthophosphate bioceramics, Ceramics International, $41(2015)$ 13913-13966. 
[22] J. Liu, C. Gao, P. Feng, S. Peng, C. Shuai, Selective laser sintering of $\beta$ TCP/nano-58S composite scaffolds with improved mechanical properties, Materials \& Design, 84 (2015) 395-401.

[23] F. Liu, C. Vyas, G. Poologasundarampillai, I. Pape, S. Hinduja, W. Mirihanage, P. Bartolo, Structural evolution of PCL during melt extrusion 3D printing, Macromolecular Materials and Engineering, (2017).

[24] J. Ahmed, R. Auras, T. Kijchavengkul, S.K. Varshney, Rheological, thermal and structural behavior of poly ( $\varepsilon$-caprolactone) and nanoclay blended films, Journal of food engineering, 111 (2012) 580-589.

[25] J.F.M. Almeida, A.L.N. Silva, V.A. Escócio, A.H.M. Thomé, A.M.F. Sousa, C.R. Nascimento, L.C. Bertolino, Rheological, mechanical and morphological behavior of polylactide/nano-sized calcium carbonate composites, Polymer Bulletin, 73 (2016) 3531-3545.

[26] M.A. Manchado, J. Biagiotti, J.M. Kenny, Rheological behavior and processability of polypropylene blends with rubber ethylene propylene diene terpolymer, Journal of Applied Polymer Science, 81 (2001) 1-10.

[27] M.M. Rueda, M.-C. Auscher, R. Fulchiron, T. Périé, G. Martin, P. Sonntag, P. Cassagnau, Rheology and applications of highly filled polymers: a review of current understanding, Progress in Polymer Science, 66 (2017) 22-53.

[28] H.A. Barnes, A review of the rheology of filled viscoelastic systems, Rheology Reviews, (2003) 1-36.

[29] T. Kaully, A. Siegmann, D. Shacham, Rheology of highly filled natural $\mathrm{CaCO}_{3}$ 
composites. II. Effects of solid loading and particle size distribution on rotational rheometry, Polymer Composites, 28 (2007) 524-533.

[30] S.P.M. Silva, P.S. Lima, J.M. Oliveira, Rheological behaviour of cork-polymer composites for injection moulding, Composites Part B: Engineering, 90 (2016) 172178. 


\section{Figure captions}

Figure 1: Schematic of (a) screw-assisted extrusion printhead (b) polymer printing process

Figure 2: Effect of frequency on the storage modulus, G', and Loss Modulus, G' at $80^{\circ} \mathrm{C}$ for (a) PCL (b) PCL/HA 5wt\% (c) PCL/HA 10wt $\%$ (d) PCL/HA $20 \mathrm{wt} \%$ (e) PCL/TCP 5wt\% (f) PCL/TCP 10wt\% (g) PCL/TCP 20wt\% (h) comparison of all blends at $80^{\circ} \mathrm{C}$

Figure 3: Effect of frequency on the storage Modulus, G', and Loss Modulus, G', as a function of temperature for (a) PCL (b) PCL/HA 5wt\% (c) PCL/HA 10wt\% (d) PCL/HA 20wt\% (e) PCL/TCP 5wt\% (f) PCL/TCP 10wt\% (g) PCL/TCP 20wt\%

Figure 4: Loss factor of (a) PCL/HA blends and (b) PCL/TCP blends at $80^{\circ} \mathrm{C}$

Figure 5: Loss factors of (a) PCL (b) PCL/HA 5wt\% (c) PCL/HA 10wt\% (d) PCL/HA 20wt\% (e) PCL/TCP 5wt\% (f) PCL/TCP 10wt\% (g) PCL/TCP 20wt\%., for different temperatures

Figure 6: Schematic of Cole-cole plot

Figure 7: Cole-cole plot of imaginary viscosity versus real viscosity for all samples at (a) $80^{\circ} \mathrm{C}$, (b) $90^{\circ} \mathrm{C}$ and (c) $100^{\circ} \mathrm{C}$

Figure 8: Cole-cole plot of storage modulus versus loss modulus for (a) HA samples, (b) TCP samples, and (c) all blends at different temperatures

Figure 9: The effect of temperature and shear rate on shear viscosity for (a) PCL, (b) PCL/HA 5 wt $\%$, (c) PCL/HA 10 wt\%, (d) PCL/HA 20 wt\%, (e) PCL/TCP 5 wt\%, (f) PCL/TCP $10 w t \%$, and (g) PCL/TCP $20 w t \%$ 
Figure 10: The effect of ceramic contents on the shear viscosity at (a) $80^{\circ} \mathrm{C}$, (b) $90^{\circ} \mathrm{C}$, and (c) $100^{\circ} \mathrm{C}$

Figure11: Particle distribution of HA and TCP samples

Figure 12: SEM images of (A) TCP particles and, (B) HA particles and insets (a) zoom-in view of TCP particles and (b) zoom-in view of HA particles

Figure 13: The effect of particle size distribution on the shear viscosity at (a) $80^{\circ} \mathrm{C}$, (b) $90^{\circ} \mathrm{C}$, and (c) $100^{\circ} \mathrm{C}$ 
Figure 1

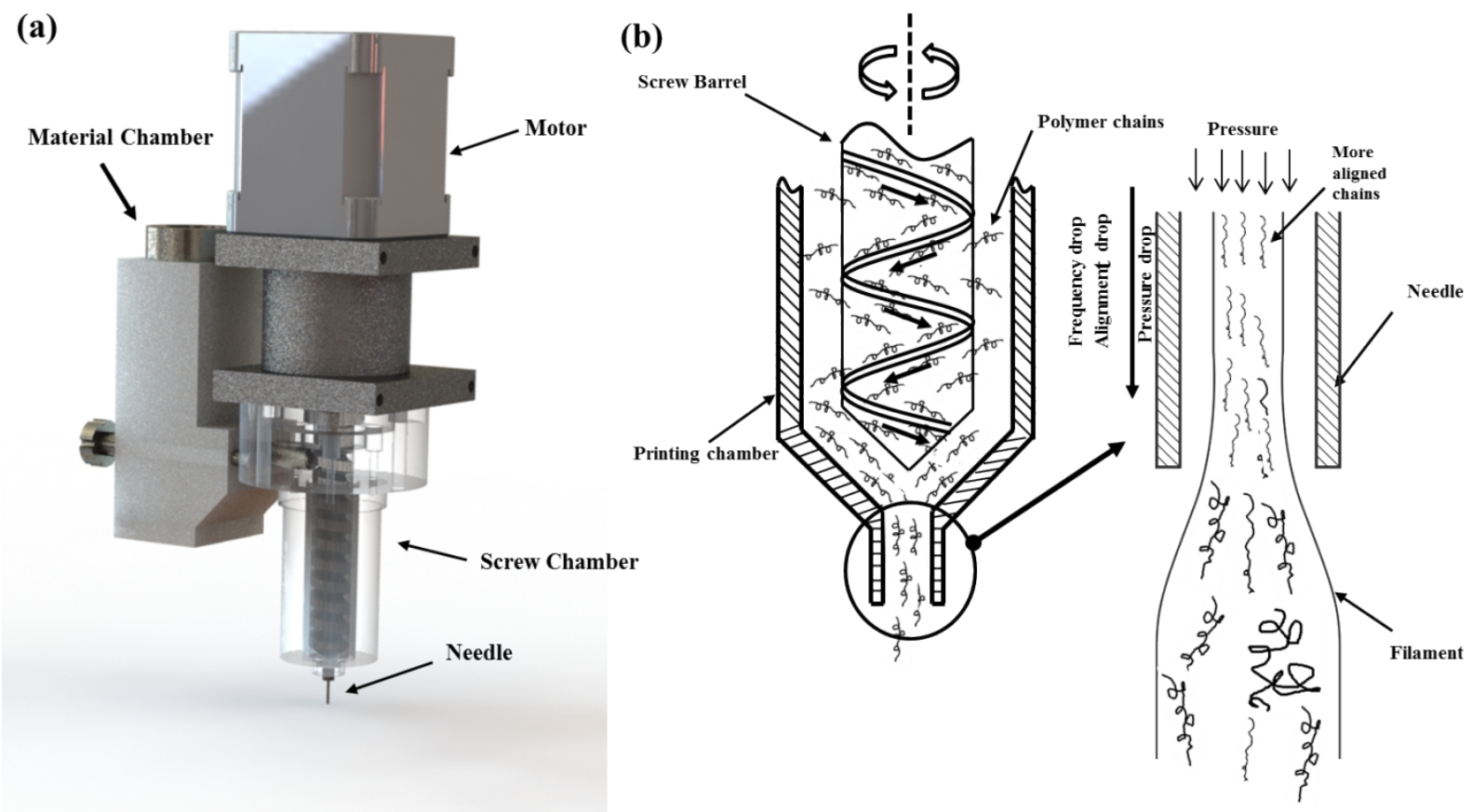




\section{Figure 2}

(a) PCL

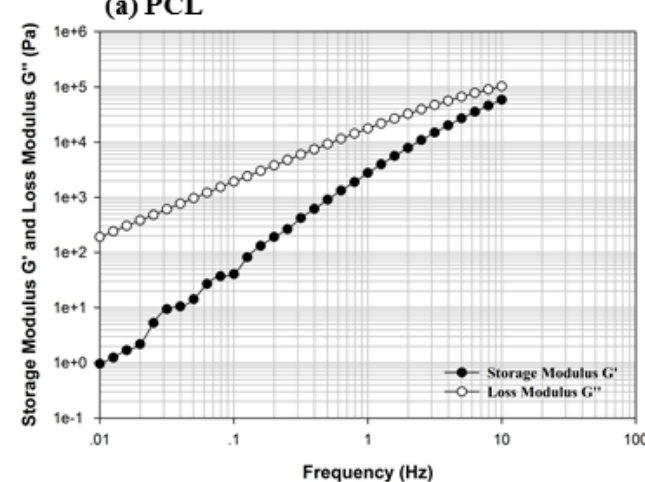

(c) PCL/HA 10 wt $\%$

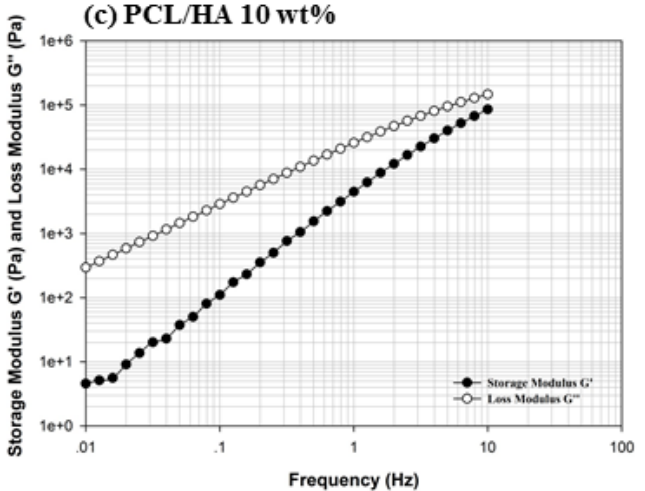

(e) PCL/TCP 5 wt $\%$

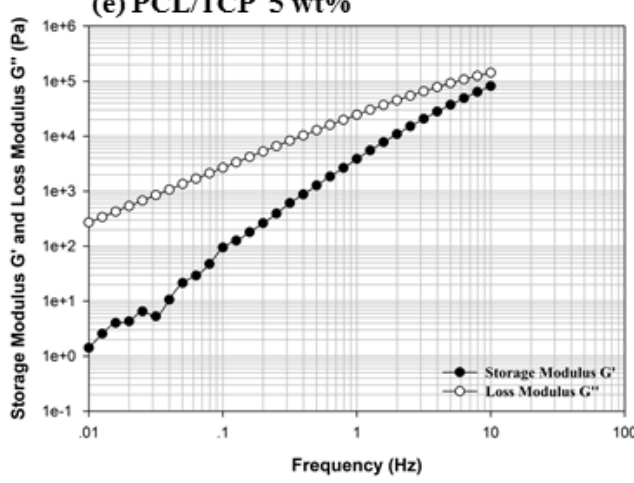

(g) PCL/TCP $20 \mathrm{wt} \%$

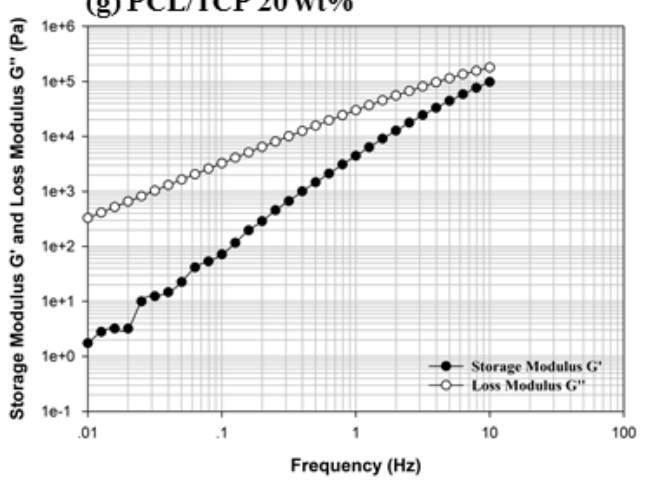

(b) PCL/HA 5 wt $\%$

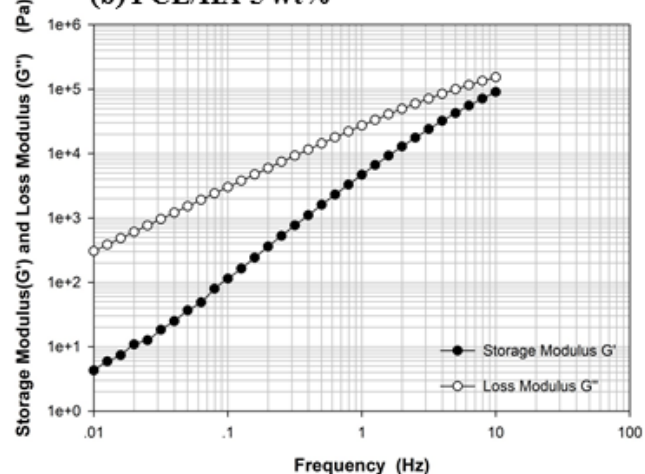

(d) PCL/HA 20 wt $\%$

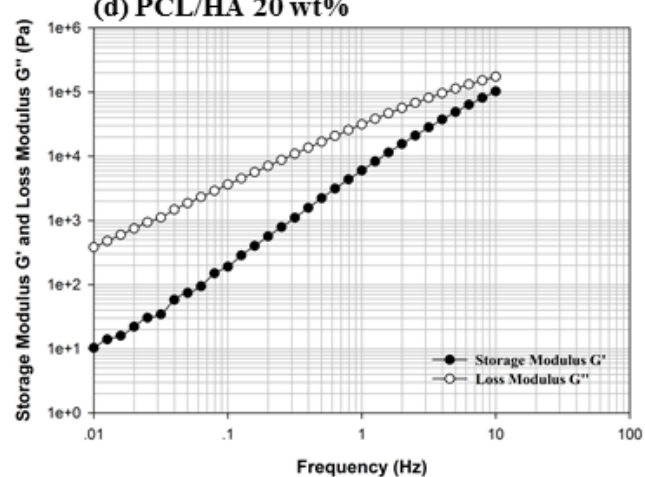

(f) PCL/TCP 10 wt $\%$

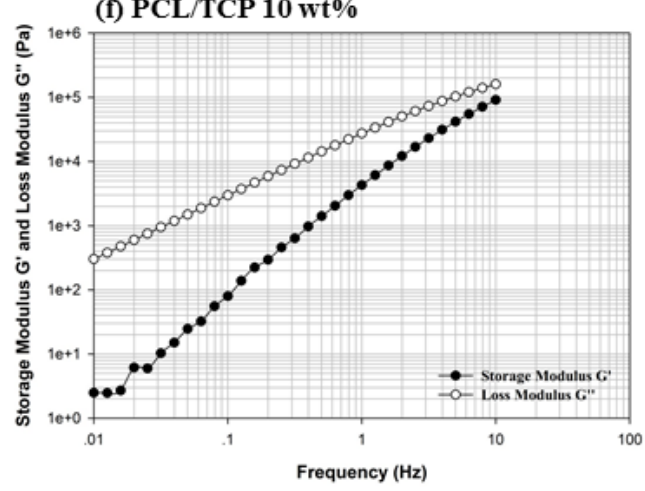

(h) Comparison

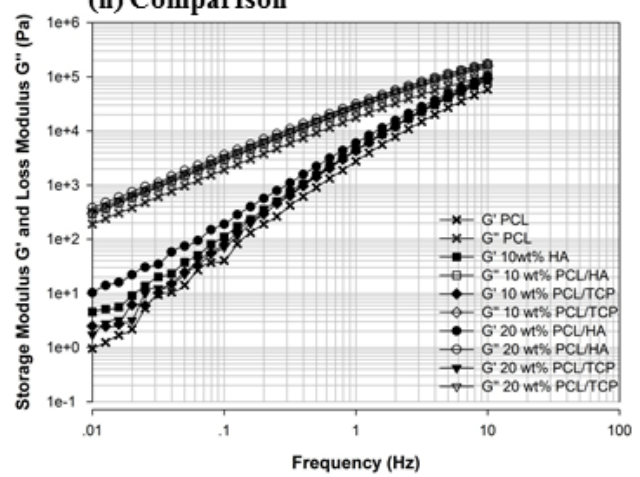


Figure 3
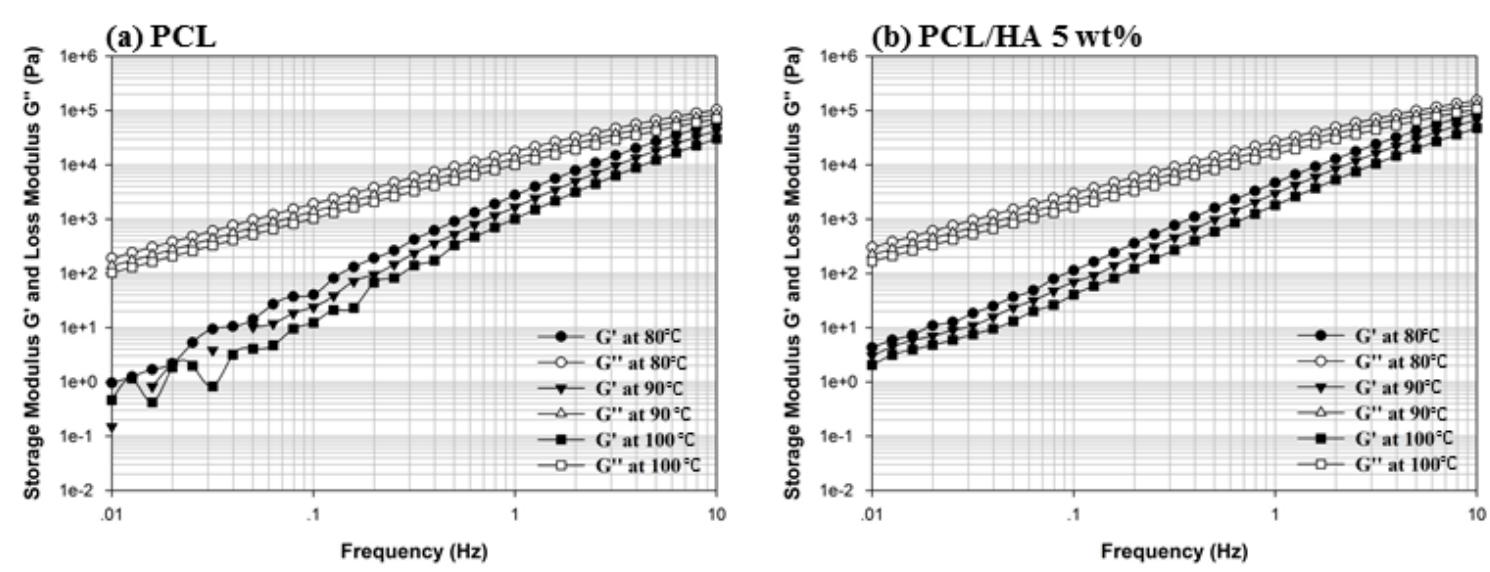

(c) PCL/HA 10 wt $\%$

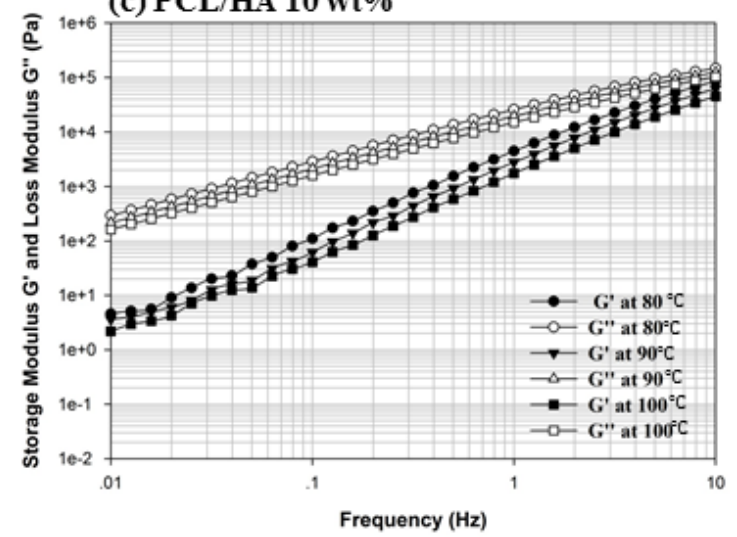

(d) PCL/HA $20 \mathrm{wt} \%$

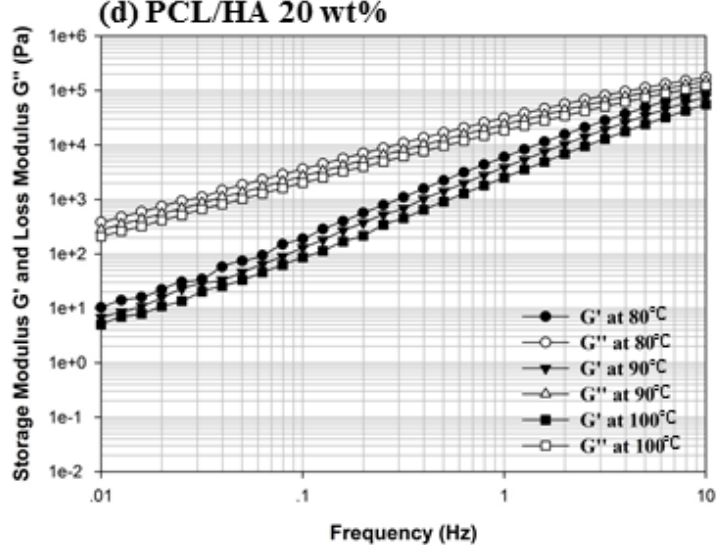

(e) PCL/TCP 5 wt $\%$
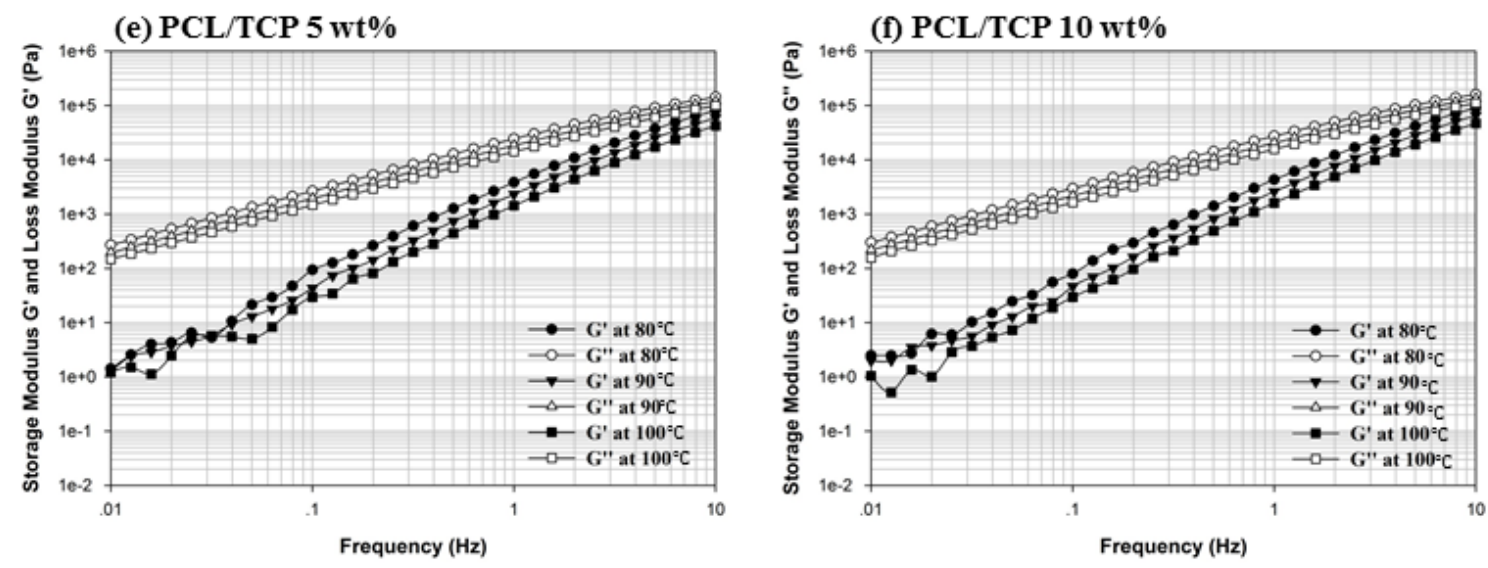

(g) PCL/TCP 20 wt $\%$

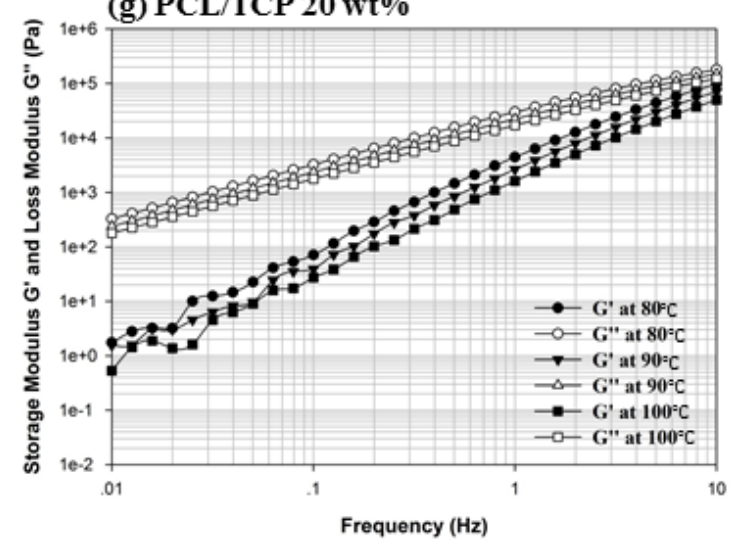


Figure 4
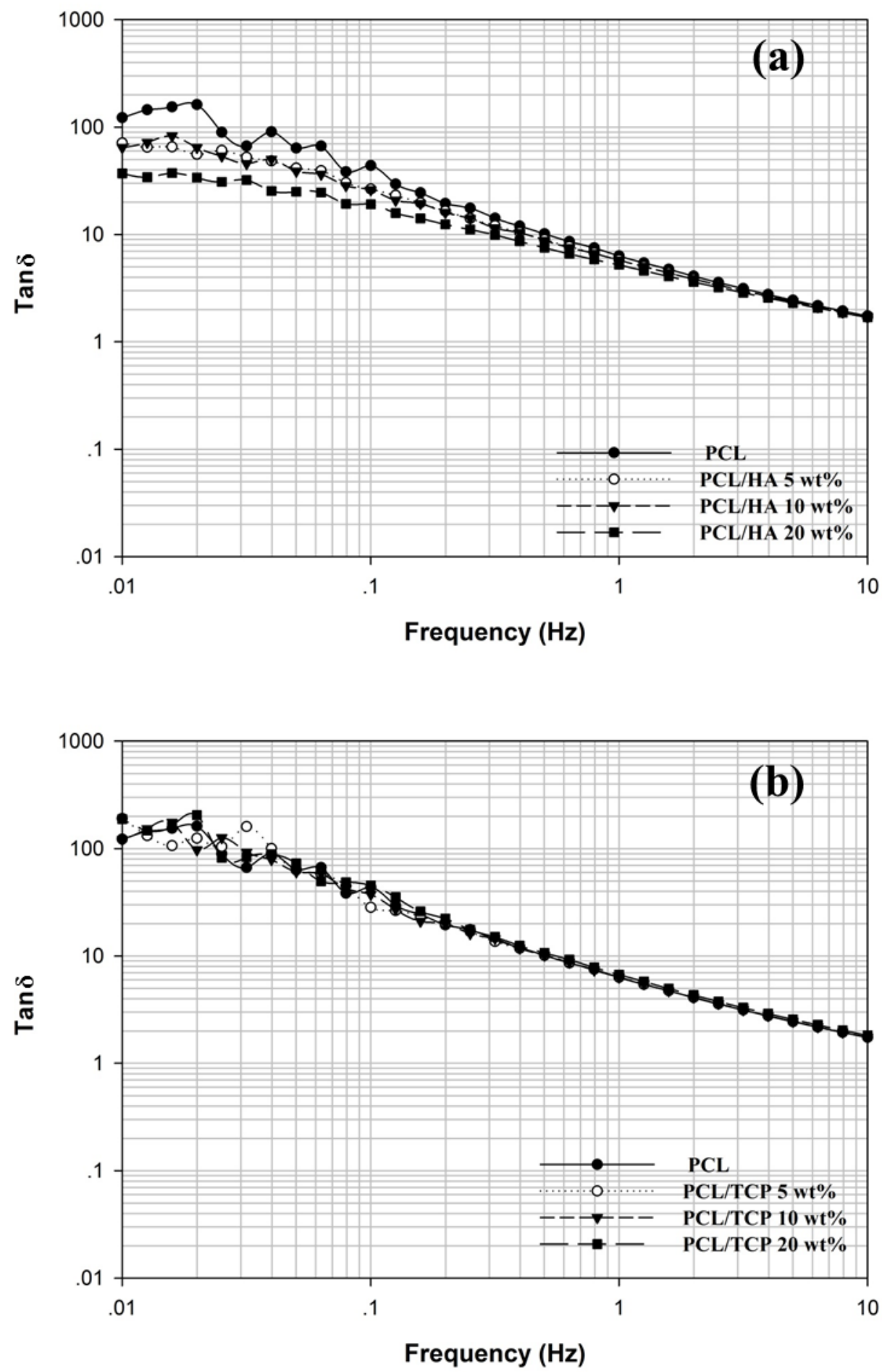
Figure 5
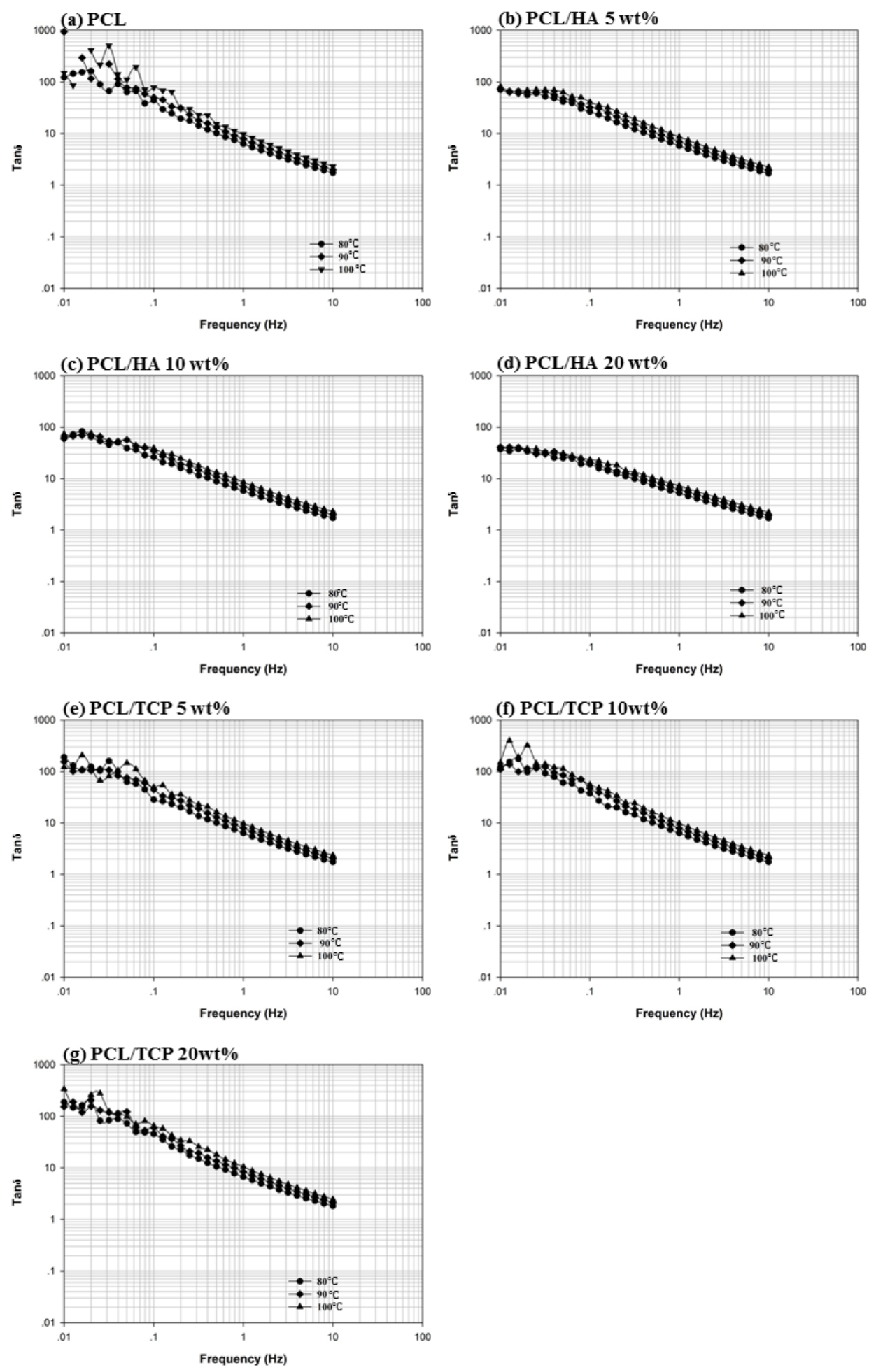
Figure 6

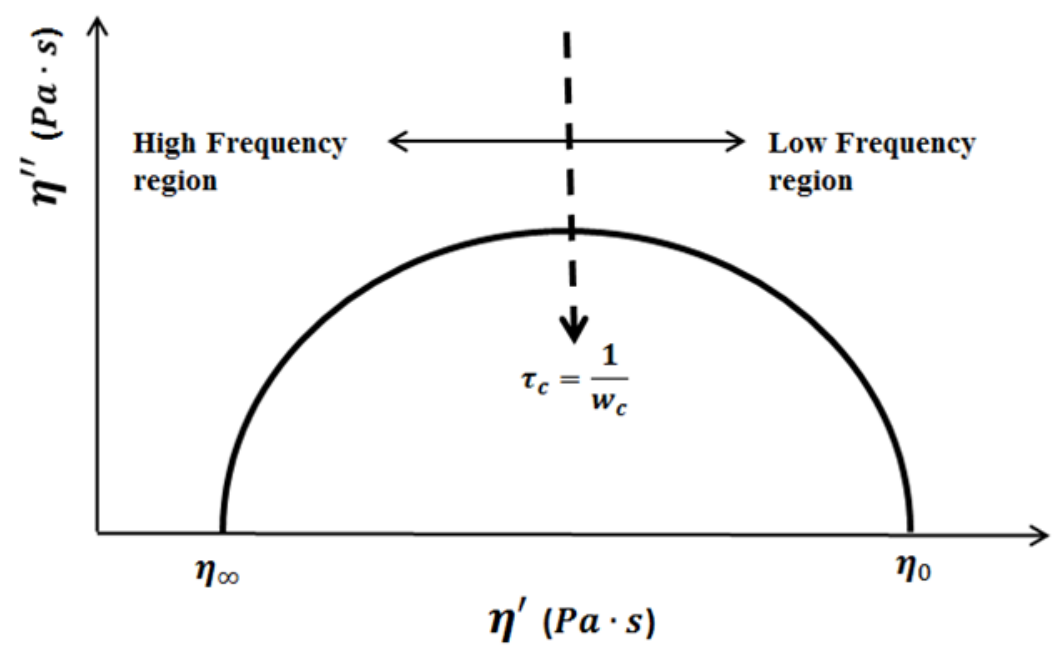


Figure 7
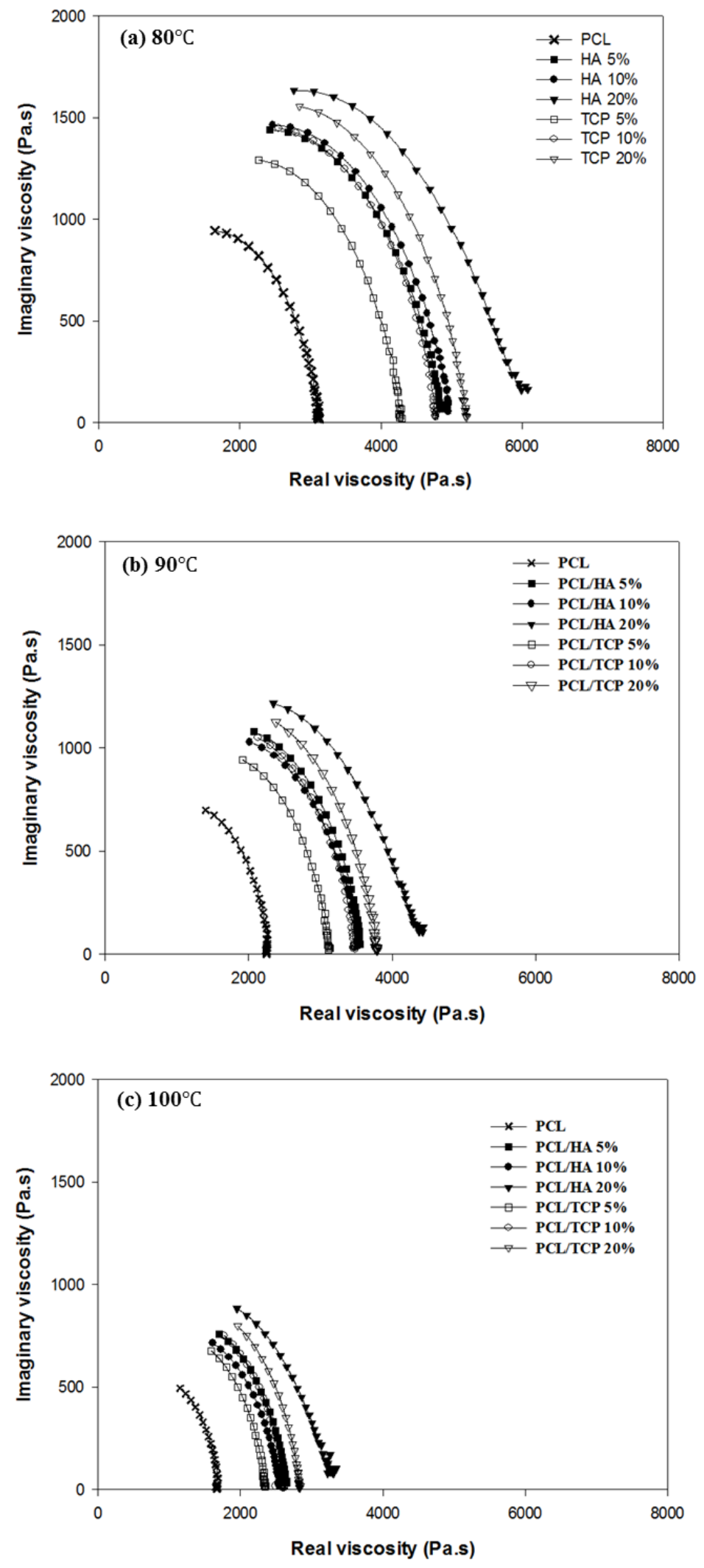
Figure

8
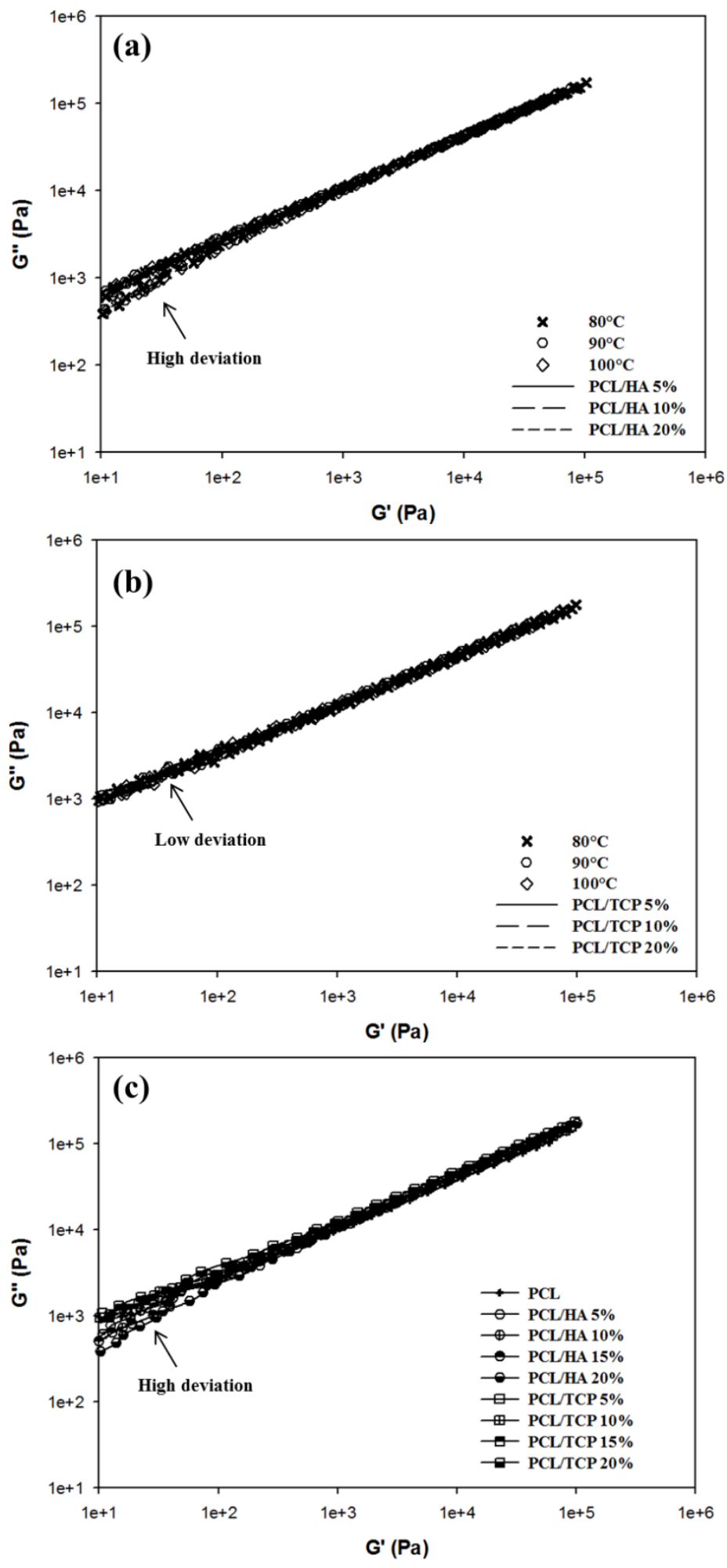
Figure 9
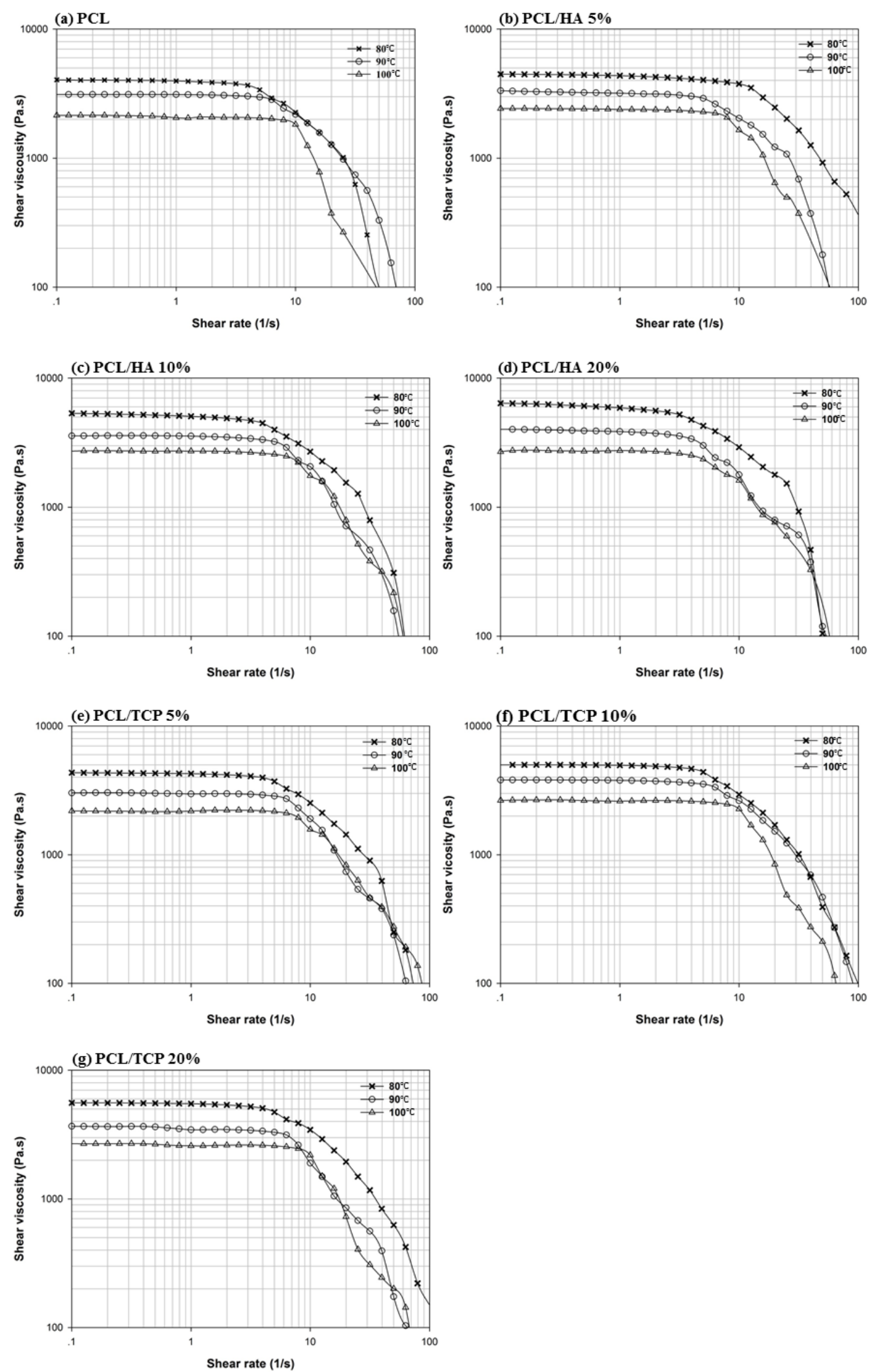
Figure 10
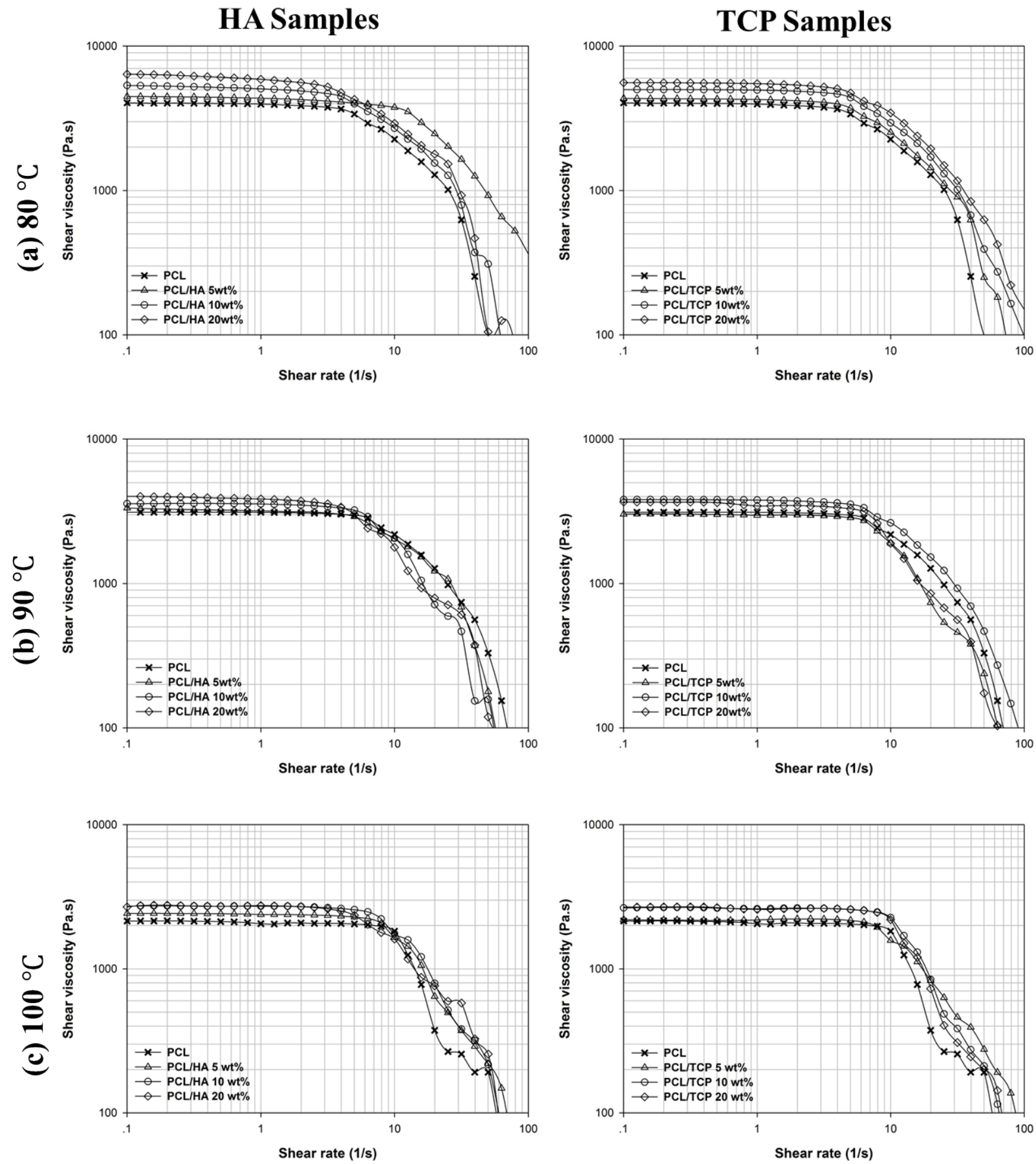
Figure 11

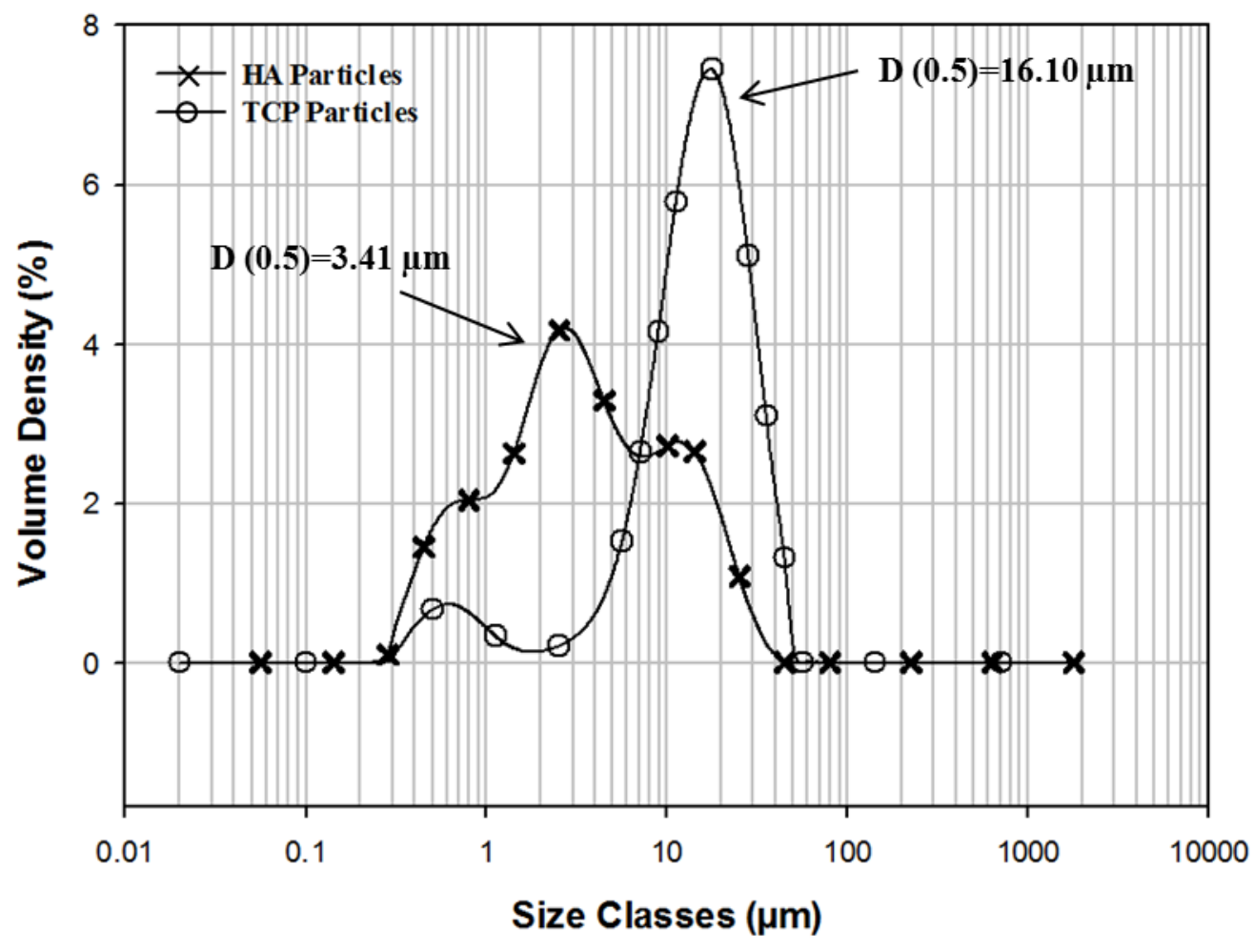


Figure 12

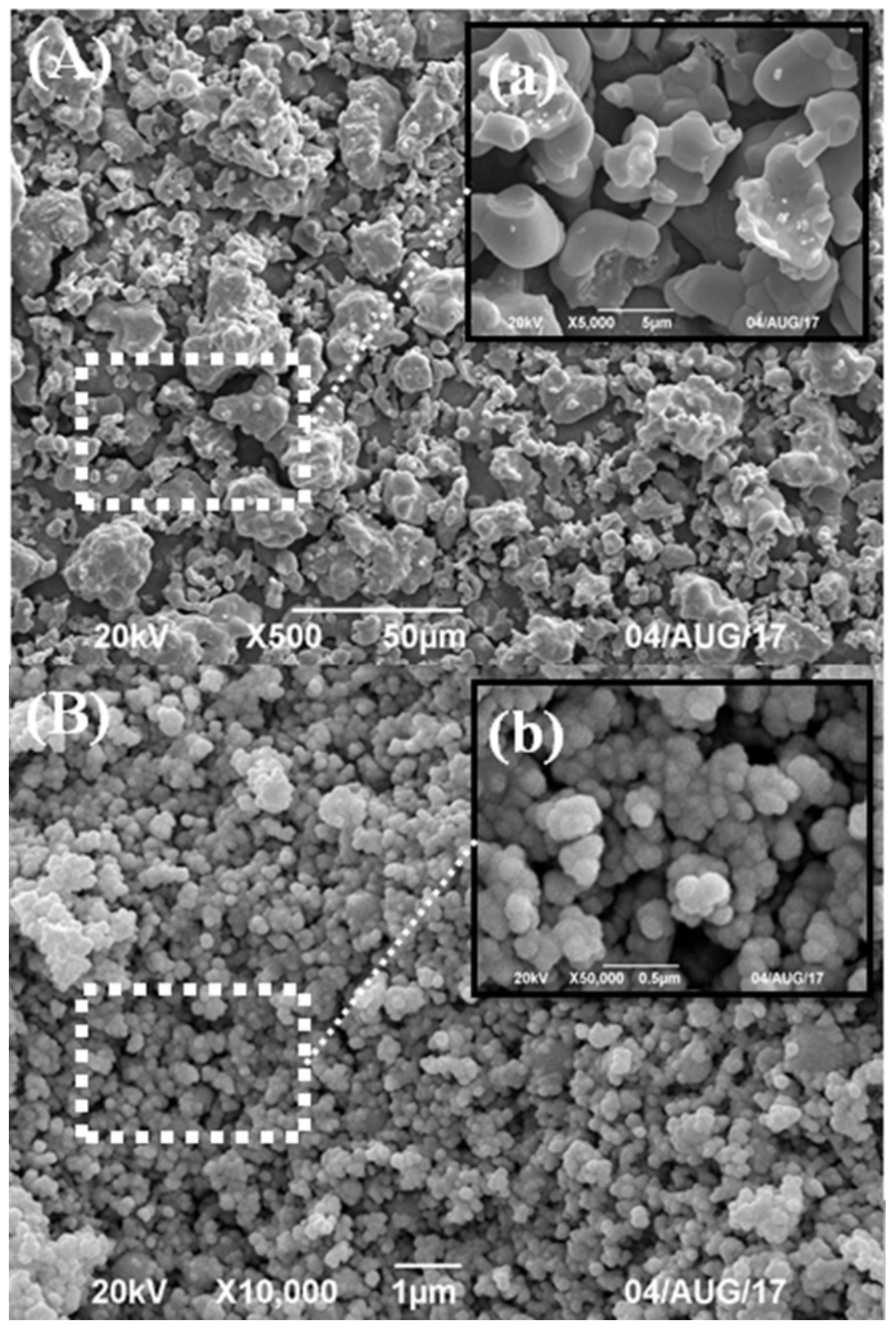


Figure 13

(a) $80^{\circ} \mathrm{C}$

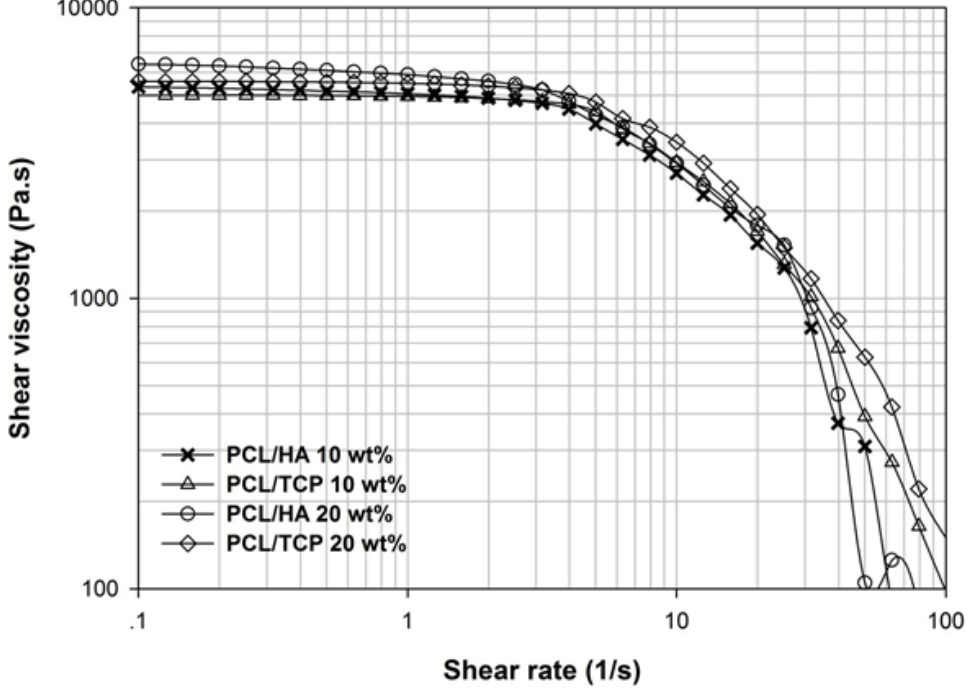

(b) $90^{\circ} \mathrm{C}$

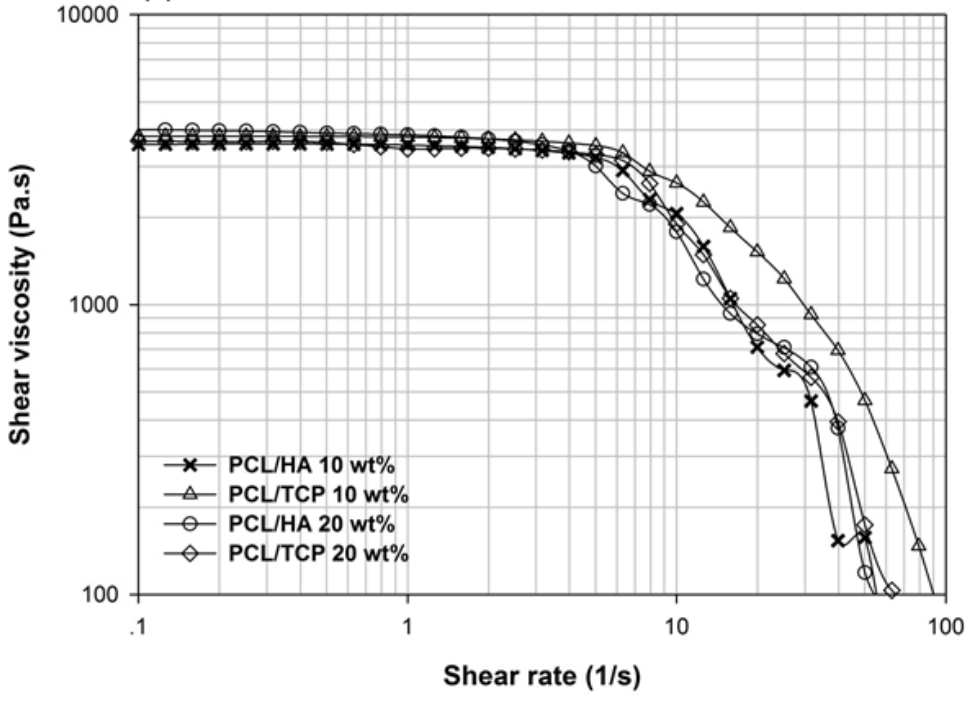

(c) $100^{\circ} \mathrm{C}$

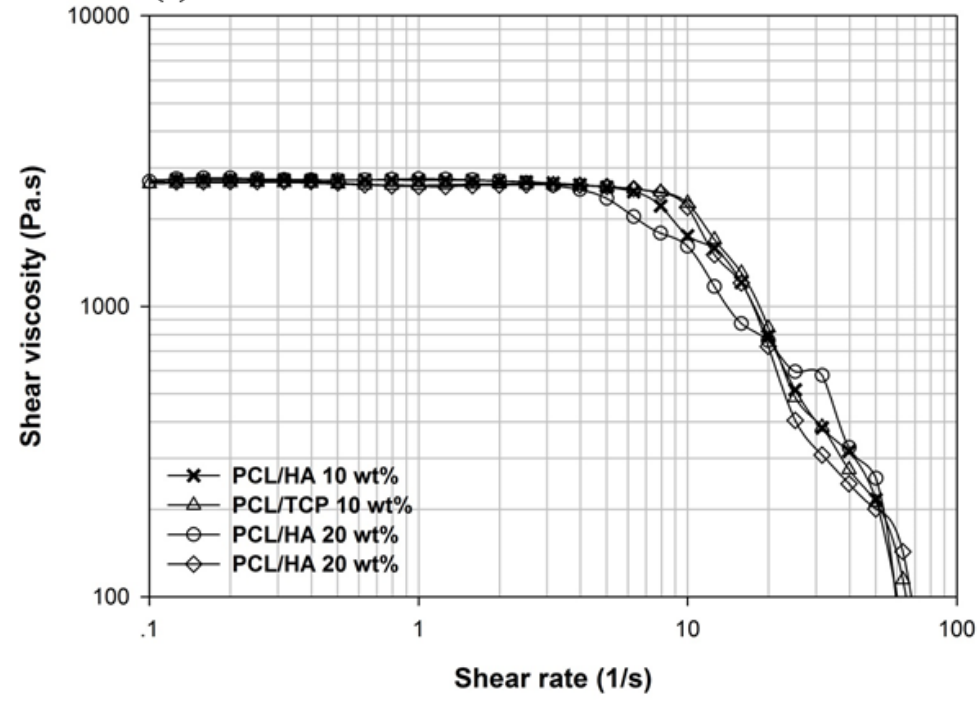




\section{Table captions}

Table 1: TGA analysis of PCL/HA and PCL/TCP for all concentrations

Table 2: Slope values of the storage modulus versus frequency and loss modulus versus frequency curves

Table 3: Physical characteristics of HA and TCP 
Table 1

\begin{tabular}{lccc}
\hline & Designed concentrations (wt\%) & Measured concentrations (wt\%) & Degradation temperature $\left({ }^{\circ} \mathrm{C}\right)$ \\
\hline PCL & 0 & 0.09 & 402.00 \\
PCL/HA & 5 & 4.89 & 406.10 \\
PCL/HA & 10 & 13.24 & 408.10 \\
PCL/HA & 20 & 19.61 & 396.40 \\
PCL/TCP & 5 & 5.80 & 406.80 \\
PCL/TCP & 10 & 13.83 & 406.4 \\
PCL/TCP & 20 & 19.37 & 398.20 \\
\hline
\end{tabular}


Table 2

\begin{tabular}{lcc}
\hline Samples & $G^{\prime}$ & $G^{\prime}$, \\
\hline PCL & 1.64 & 0.95 \\
PCL/TCP $10 \mathrm{wt} \%$ & 1.63 & 0.96 \\
PCL/TCP $20 \mathrm{wt} \%$ & 1.64 & 0.96 \\
PCL/HA $10 \mathrm{wt} \%$ & 1.55 & 0.95 \\
PCL/HA $20 \mathrm{wt} \%$ & 1.46 & 0.93 \\
\hline
\end{tabular}


Table 3

\begin{tabular}{|c|c|c|}
\hline Particle Distribution $(\mu \mathrm{m})$ & HA (\%) & ТCP (\%) \\
\hline$<1$ & 17.75 & 5.91 \\
\hline 5 & 47.51 & 5.19 \\
\hline 10 & 16.01 & 18.70 \\
\hline 15 & 10.63 & 26.71 \\
\hline 20 & 4.02 & 14.69 \\
\hline 25 & 2.54 & 12.76 \\
\hline 35 & 1.44 & 12.33 \\
\hline$>35$ & 0.1 & 3.67 \\
\hline Sum & 100 & 100 \\
\hline Average particle size $(\mu \mathrm{m}) *$ & 3.41 & 16.10 \\
\hline Surface average size $D(3,2)(\mu \mathrm{m})$ & 1.96 & 5.75 \\
\hline Volume average size $D(4,3)(\mu \mathrm{m})$ & 6.26 & 17.60 \\
\hline Specific Surface area $\left(m^{2} / k g\right)$ & $3.07 \times 10^{3}$ & $1.04 \times 10^{3}$ \\
\hline
\end{tabular}

